\title{
Managing and Applying Innovation in New Product Development - Strategies and Initiatives Managing and Applying Innovation in NPD
}

Pratap Chandra Mandal, Indian Institute of Management - Shillong, India

\begin{abstract}
Companies require introducing new products in the market and manage product innovation properly to remain ahead in the competition. Innovative firms should adopt a customer-centered approach towards managing innovation. They require understanding individual differences of customers in their readiness to accept innovation and roles of product characteristics in adoption of innovation among customers. Managing innovation requires collaboration and proper coordination. Top management support is imperative for new product development. Firms should adopt an approach of team-based innovation. Also, firms should handle innovation in a systematic rather than in a haphazard manner. Innovative companies should also consider opportunities during turbulent times and invest wisely to utilize those opportunities. Firms may also benefit by targeting individuals at the bottom of the pyramid with innovation. Companies require considering all these approaches towards managing innovation in new product development to perform and excel in the competition.
\end{abstract}

\section{KEYWORDS}

Bottom Of Pyramid, Cross-Functional Team, Customer-Centered Innovation, Innovation Management System, Systematic Innovation, Team-Based Innovation, Technological Obsolescence, Top Management Support,

\section{INTRODUCTION}

New products are the lifeblood of any organization (Barone \& Jewell, 2013). Companies require doing continual innovation to remain competitive and relevant in the market. However, innovation in new product development is risky and many new products fail (Aboulnasr, Narasimhan, Blair, \& Chandy, 2008). Once successful in innovation and after being introduced in the market, companies want their products to enjoy long and happy lives. Every product passes through a number of stages in its life cycle. Each stage poses new challenges and requires different marketing strategies and planning (Crawford \& Di Benedetto, 2011). However, companies that excel in innovating, developing, and managing new products are successful in the long run. Innovation in new product development faces two major challenges. First, once introduced, all new products eventually decline, and companies need to do continual innovation to introduce new products and replace the aging ones (Dahan \& Hauser, 2002). Also, companies need to adapt its marketing strategies in the face of changing tastes, technological obsolescence, and competition as products pass through different stages (Jhang, Grant, \& Campbell, 2012). Companies should be ready to accept the challenges and adopt innovation to succeed in the long run. Companies should also take a holistic approach to managing innovation in new product

This article, originally published under IGI Global's copyright on July 1, 2019 will proceed with publication as an Open Access article starting on February 3, 2021 in the gold Open Access journal, International Journal of R\&D Innovation Strategy (converted to gold Open Access January 1, 2021), and will be distributed under the terms of the Creative Commons Attribution License (http://creativecommons.org/licenses/ by/4.0/) which permits unrestricted use, distribution, and production in any medium, provided the author of the original work and original publication source are properly credited. 
development. Successful innovation in new product development requires a customer-centered, teambased, and systematic effort (Mansur, Suliyanto, \& Rahab, 2019). The paper discusses about the different approaches in managing innovation in new product development. It focuses on B2C markets. Product innovation in B2C markets poses a number of challenges which are discussed. The aim of the discussion is to address the specific issues related to innovation for new product development in turbulent times and targeting individuals at the bottom of the pyramid with innovations.

The paper is structured as follows:

Section 2 focuses on the readiness of organizations to adopt innovation. Product innovation needs to be based on customer requirements and this aspect is discussed in section 3 with subsections 3.1 and 3.2 focusing on individual differences of customers in innovativeness and roles of product characteristics in adoption of innovation among customers respectively. Innovation in new product development also requires a team-based approach and this aspect is discussed in section 4 . Systematic approach towards innovation in new product development is discussed in section 5. It is imperative to innovate in turbulent times and this is discussed in section 6. Section 7 focuses on product innovation in emerging economies and individuals at the bottom of the pyramid. Section 8 focuses on the discussions done throughout the paper with sub-section 8.1 focusing on managerial implications and sub-section 8.2 focusing on contributions of the paper. Section 9 concludes the discussions with sub-section 9.1 focusing on avenues for future research.

\section{ORGANIZATION'S READINESS TO ADOPT INNOVATION}

Organizations should be willing and ready to adopt innovation (Rubera \& Kirca, 2012). Top management support is required for innovation. Innovation demand financial, human, and other resources on a regular basis. This is not possible without support from the top management who are involved in making such decisions (Mansur et al., 2019). Organizations also require encouraging innovators. The innovators would want to identify firms who would be willing to adopt their innovations (Kahn, 2018). Adoption of innovation is associated with a number of variables in the organization's environment (community progressiveness, community income), the organization itself (size, profits, willingness to change, pressure to change), and the administrators (education level, age, sophistication) (Jhang et al., 2012). Other factors in the external environment may also affect an organization's willingness to adopt innovation. These factors may include funding received from the government and competition from firms in the industry (Aboulnasr et al., 2008). A controversial or innovative product may also be eliminated because of negative public opinion.

\section{CUSTOMER-CENTERED INNOVATION IN NEW PRODUCT DEVELOPMENT}

Innovation in new product development should be customer-centered. While generating ideas for innovation and developing new products, companies have a myopic view and depend heavily on technical research in their R\&D laboratories (Landwehr, Wentzel, \& Herrmann, 2013). However, companies should realize that innovation starts with a thorough understanding of customer value, requirements, and preferences (Gamble, McAdam, \& Brennan, 2019). Customer-centered innovation for new product development focuses on finding new ways and solutions for customer problems, creating more satisfying customer experiences, and delighting them (Martin, 2011).

Research studies have found that the most effective innovation for new products takes place when new products solve major customer problems, offer a compelling value proposition for customers, and are differentiated from products of the same category (Aboulnasr et al., 2008). Studies have also proved conclusively that those new-product innovation processes are more successful which directly engage their customers. Such processes had twice the return on assets and triple the growth in operating income of firms that did not engage their customers (Barone \& Jewell, 2013). Thus, customer involvement and engagement have positive effects on innovation in new product development and product success (Brown, 2009). 
Procter \& Gamble $(\mathrm{P} \& \mathrm{G})$ is a company which does a lot of innovation with a focus on customers. $P \& G$ understands its customer requirements and involves them in generating new ideas for innovation (Berner, 2008). The success in innovation and new products for consumer package goods industry is only about 15 to 20 percent. Compared to that, $P \& G$ 's success rate is over 50 percent (Berner, 2009). According to A.G. Lafley, the former CEO of P\&G, the company has been able to attain this success because $P \& G$ focuses on understanding customer requirements and preferences. Previously, $P \& G$ used to push new products to customers without first understanding their requirements (Lafley \& Charan, 2009). At present, $P \& G$ employs an immersion process called "Living It" in which researchers go to the extent of staying with customers for a continuous time period to understand their requirements and envision product ideas based directly on their requirements (Berner, 2009). P\&G employees also do mystery shopping by visiting stores for gaining customer insights, a process they call as "Working It" (Berner, 2008). P\&G invests much more than any other company in the world to conduct consumer research and gain customer insights. $P \& G$ interacts with more than five million customers in 100 countries every year (Berner, 2009). It conducts more than 20000 research studies every year to understand its customers. It invests more than $\$ 400$ million annually in a process which P\&G has named as "consumer understanding". "We figured out how to keep the consumer at the center of all our decisions", concludes Lafley. "As a result, we don't go far wrong" (Lafley \& Charan, 2009).

The example of $P \& G$ proves that companies cannot confine their research in R\&D laboratories. Innovative companies need to go out and interact with customers to understand what customers really want (Barone \& Jewell, 2013). Customer-centered innovation in new product development begins and ends with understanding customer requirements and engaging them in the process of innovation.

\subsection{Individual Differences of Customers in Innovativeness}

Companies should remember that customers differ greatly in their readiness to accept innovation and to go for new products (Rogers, 2003). Customers also differ based on their needs, requirements, and preferences. Based on the level of acceptance, customers may be classified as innovators, early adopters, early mainstream, late mainstream, and lagging adopters (Crawford \& Di Benedetto, 2011). The classification of customers based on acceptance of innovation indicates that companies should research the characteristics of customers with respect to acceptance of innovation and target initial marketing efforts accordingly. The marketing efforts should match with the customer requirements. Otherwise, new products will not be a success.

\subsection{Roles of Product Characteristics in Adoption of Innovation Among Customers}

The characteristics of new products influence the rate of adoption among customers (Crawford \& Di Benedetto, 2011). Some products gain acceptance almost immediately after the product launch, some others take time to gain acceptance. For example, some products like Apple's iPod, iPad, and iPhone were successful in gaining acceptance among customers and flew off the retailers' shelves immediately after the products were introduced in the market (Rubera \& Kirca, 2012). On the other hand, products like HDTV took time to gain acceptance. HDTVs were introduced in the United States in the 1990s. However, the product had a low acceptance rate initially and by 2007 , only 12 percent of U.S. households owned a high-definition set. Later, HDTV penetration reached 66 percent in 2012 (Winslow, 2012).

Several product characteristics may influence an innovation's rate of adoption among customers. These characteristics include relative advantage, compatibility, complexity, divisibility, and communicability (Crawford \& Di Benedetto, 2011). Companies should research about all these characteristics and aim to incorporate them in new products. Other characteristics which influence the rate of adoption include initial and ongoing costs, risk and uncertainty involved in product usage, and social approval of the products (Rubera \& Kirca, 2012). Innovative firms should research all these factors during innovation and new product development and at various stages of their marketing programs. 


\section{TEAM-BASED INNOVATION IN NEW PRODUCT DEVELOPMENT}

Innovation in new product development requires collaboration and proper coordination among various departments and functions of an organization (Landwehr et al., 2013). Some companies organize innovation in new product development into a number of sequential steps. In this sequential process, one department works individually to finish its job before passing along the new product to the next department. This orderly process helps in cases of complex and risky projects. However, the process may be slow. In fast-changing, dynamic, and highly competitive markets, such slow processes may result in product failures, lost sales and profits, and unutilized opportunities (Martin, 2011).

Many companies employ a team-based innovation in new product development to quicken the process and launch the product quickly in the market (Hauser, Tellis, \& Griffin, 2006). In this approach, departments work closely in collaboration and in cross-functional teams. This approach streamlines the process of innovation and product development, saves valuable time, and increases efficiency and effectiveness (Rajapathirana \& Hui, 2018). Instead of the various departments going through the stages of development one after another, the company develops a team consisting of employees from various departments and the team members maintain proper coordination among themselves from inception till the end (Landwehr et al., 2013). Such teams are formed by including people from marketing, design, manufacturing, finance, and legal departments, and even supplier and customer companies (Psomas, Kafetzopoulos, \& Gotzamani, 2018). In a sequential process, a bottleneck in any of the stages may slow down the entire process. However, this problem is eliminated in a team-based approach, and if one area faces problems, the team works quickly and promptly to resolve them (Hauser et al., 2006).

The team-based approach however, has its own limitations. More organizational tension and confusion may be created if proper coordination among team members is missing (Landwehr et al., 2013). However, in rapidly changing industries facing increasingly shorter product life cycles, the benefits far exceed the risks. Companies that combine a customer-centered approach with a teambased approach are able to innovate faster and gain a competitive advantage by launching the right products in the market faster (Hauser et al., 2006).

\section{SYSTEMATIC INNOVATION IN NEW PRODUCT DEVELOPMENT}

Companies require handling innovation in new product development in a systematic rather than in a compartmentalized and haphazard manner (Bessant, Moslein, \& Stamm, 2009). Unless a proper and systematic process is in place, few new ideas will be generated and many innovative ideas will be lost. To solve these issues, companies may develop and implement an innovation management system to collect, review, evaluate, and manage innovative ideas (Crawford \& Di Benedetto, 2011).

A company requires appointing an employee from the senior management as the innovation manager. It can set up online management software and encourage all stakeholders to become involved in the innovation process for new product development (Aboulnasr et al., 2008). The stakeholders may include employees, distributors, dealers, and suppliers. It can appoint a cross-functional innovation management committee to evaluate the ideas proposed for innovation and select the best ideas to focus on. It can also initiate programs which reward individuals who suggest the best ideas (Barone \& Jewell, 2013).

The approach based on innovation management system results in favorable outcomes (Bessant et al., 2009). It helps in building a culture of innovation in the organization. It also helps in generation of a large number of innovative ideas from which the most effective ones may be chosen. The effective ideas may be more systematically developed producing more new product successes. Also, innovative ideas will not be lost because of lack of support and encouragement (Dahan \& Hauser, 2002).

Success in innovation for new products requires more than generating new ideas, turning them into products, and finding customers for them. It requires a holistic approach for finding new ways 
to generate ideas which create better value and experiences for customers (Troy, Hirunyawipada, \& Paswan, 2008). The discussions also indicate that successful innovation for new product development requires commitment from everyone in the organization (Tellis, Prabhu, \& Chandy, 2009). In companies known for innovation, the entire culture in the organization encourages, supports, and rewards innovation. Such companies include Apple, 3M, GE, Google, and Procter \& Gamble.

Google has a strong focus on innovation. Many companies adopt a cautious and step-by-step approach towards innovation. However, innovation and new product development at Google move at a lightning speed (Brinkman, 2013). It follows a chaotic innovation process through which a number of diverse products have been launched. The products range from an e-mail service (Gmail), a blog search engine (Google Blog Search), and a photo sharing service (Google Picasa) to a universal platform for mobile phone applications (Google Android), projects for mapping and exploring the world (Google Maps and Google Earth), a cloud-friendly web browser (Chrome), and even an early warning system for flu outbreaks (FluTrends) (Epps, 2013). Google is able to innovate such diverse projects because of its passion for innovation and assisting people find and use information.

At Google, innovation is the responsibility of each and every employee. Google engineers are encouraged to spend 20 percent of their time developing their own innovative ideas for new products (Stone, 2013). During the selection process, Google asks the potential employees how they would change the world if they worked for Google. Employees at Google are inquisitive with a thirst for knowledge. "Thinking - and building - on that scale is what Google does", comments one analyst. "This, after all, is the company that wants to make available online every page of every book ever published. Smaller-gauge ideas die of disinterest" (Burrows, 2012). At Google, innovation comes naturally because it is a part of the company's DNA. "It's in the air", says the analyst, "in the spirit of the place" (Salter, 2008).

\section{INNOVATION FOR NEW PRODUCT DEVELOPMENT IN TURBULENT TIMES}

Managements of companies hesitate to invest in innovation and new product development when they face uncertainties and financial difficulties (Liu, Deng, Wei, Ying, \& Tian, 2019). Some companies are tempted to reduce investment in innovation and new product development during turbulent times (Rigby, Gruver, \& Allen, 2009). However, such strategies are shortsighted and are not successful in the long run. By reducing investment on innovation, companies may have monetary gains in the short run. However, in the long run, a company becomes less competitive once the economic downturn or turbulence is over (Hayes, 2009). Experts suggest that tough times may demand higher investment in innovation and new product development as companies struggle to better align their marketing strategies and offerings with changing consumer needs and tastes (Hayes, 2009; Rigby et al., 2009). In turbulent times, focus on innovation may help companies to do what others hesitate to do, and consequently to become more competitive and to position themselves better for the future.

Innovative companies like Google, Apple, 3M, Amazon, and Samsung maintain a strong focus on innovation even during economic downturns (Rubera \& Kirca, 2012). For example, Apple developed its blockbuster iPod, iPhone, and iTunes innovations in tough times it faced during economic downturn. The innovations helped Apple not only to survive but also to flourish during tough times. Strong focus on innovation helped Apple to become an innovative powerhouse it is today (Rubera \& Kirca, 2012). The above examples prove that companies should aim for continual innovation irrespective of good or bad times. Innovative firms may have higher returns if they invest in innovation properly during turbulent times. Companies should encourage new ideas and develop new products if they want to grow and prosper (Barone \& Jewell, 2013). 


\section{TARGETING PEOPLE AT THE BOTTOM OF THE PYRAMID WITH INNOVATION}

Experts believe that much innovation can come from developing and emerging markets like India and China (Prahalad, 2010). Individuals in emerging economies and individuals at the bottom of the pyramid have requirements which are different from that of individuals in developed economies (Afriyie, Du, \& Musah, 2019). Business expert, C.K. Prahalad believes that individuals in emerging markets are underserved by a majority of marketers. Estimates reveal that five billion individuals form the underserved market that make up the "bottom of the pyramid" (Prahalad, 2010). One study found that four billion of these individuals live on $\$ 2$ or less a day (Jane, 2009). Firms operating in such markets have enormous opportunities and should learn how to do more with less.

In Bangalore, India, Narayana Hrudayalaya Hospital charges a nominal fee of $\$ 1500$ for heart bypass surgery. The same surgery may cost 50 times as much in the United States (Jane, 2009). The hospital is able to charge such low fees because it has low labor cost and operating expenses and an assembly-line view of care. The approach adopted by the hospital works. Additionally, the mortality rates achieved by the hospital are half those of U.S. hospitals (Breen, 2007). The hospital also has free facility of operations for infants and insures 2.5 million poor Indians against serious illnesses for 11 cents a month (Breen, 2007).

Another hospital which has achieved great success by catering to the needs of individuals at the bottom of the pyramid is Arvind Eye Care System which was established by Govindappa Venkatswamy in 1976 in India (Breen, 2007). It has performed four million operations using an approach of highvolume assembly similar to that of McDonald's. Arvind Eye Care also develops an intra-ocular lens, manufactured by its subsidiary, Aurolab, at a fraction of the cost of imports (Jane, 2009). Inspired by the innovation and effort of Arvind Eye Care, U.S. firms like Sala Uno, a for-profit social enterprise based in San Francisco have replicated the Arvind model. Sala Uno has replicated the model in Mexico to carry out 133 cataract operations a month for a year. The operations were offered free of charge to those who could not afford the treatment (Jane, 2009).

Innovative firms adopt reverse innovation to transfer innovations done in developing and emerging markets to developed markets (Govindarajan \& Trimble, 2012). Dartmouth professor, Vijay Govindarajan explains that opportunities exist in focusing on the needs and requirements of customers in developing markets (Govindarajan \& Trimble, 2012). Innovations may be developed at lower costs in developing markets. The innovations may be tested in developing markets and depending on the success in those markets, the innovations may be introduced in developed markets as a cheaper alternative (Immelt, Govindarajan, \& Trimble, 2009). This reduces the investment of companies on R\&D. It is also suggested that such low-cost innovation may have public policy benefits, which can transform industries because of the development of low-cost transportation, clean water, renewable energy, micro-finance, low-cost housing, and affordable health care (Govindarajan, 2012).

Many companies have applied reverse innovation successfully. Nestlé developed low-fat Maggi brand dried noodles for emerging markets of India and Pakistan. The product was later introduced as a budget-friendly health food in New Zealand and Australia (Markides, 2012). U.S.-based Herman International is known for high-end dashboard audio systems designed by German engineers. The company developed a simpler and cheaper process to innovate products in the emerging markets of India and China. It is applying the method in innovating products in the West (Carus, 2012). Based on such methods, the company is able to sell a range of products priced from low to high. It is now targeting to innovate in infotainment systems for motorbikes, a popular form of transportation in emerging markets and around the world (Markides, 2012).

\section{DISCUSSIONS}

Innovation in new product development involves more than merely going through a number of steps. It requires to be managed properly. Companies must adopt a systematic and holistic approach to managing 
the process. Successful innovation in new product development requires a customer-centered, teambased, and systematic effort. Innovative firms should be aware that there exist individual differences among customers in accepting innovation. Customers respond differently depending on customer and product characteristics. So, different groups of customers may require different marketing approaches. Several product characteristics like relative advantage, complexity, divisibility, compatibility, and communicability may influence the adoption rate. Companies also need to realize that opportunities in innovation exist during turbulent times and in targeting individuals at the bottom of the pyramid.

The first step towards innovation for an organization is its readiness and willingness to adopt innovation. Innovative firms should be customer-centered and should have an in-depth understanding of customer requirements. To gain greater insights into customer requirements, firms should involve customers in the process of innovation. Firms should acknowledge and accept individual differences of customers in their readiness to accept innovation. Innovation also requires collaboration and proper coordination among various departments and functions of an organization. Innovative firms should adopt team-based approach to handle innovation effectively. Firms also require handling innovation in a planned and systematic manner to streamline the whole process. Such an approach will allow firms to have a holistic perspective with support and cooperation from everyone in the organization. Companies should also realize that opportunities in innovation may exist in turbulent times. They should invest wisely to utilize those opportunities. Opportunities may also exist in targeting individuals at the bottom of the pyramid with innovation. It is an untapped market and huge potential exists in such markets.

\subsection{Managerial Implications}

The discussions will sensitize managers about the importance for organizations to adopt innovation, the necessity to adopt a customer-centric and systematic approach towards innovation. They may also review and analyze the existing approaches in their companies and adopt more effective approaches. They will also realize that opportunities exist in taking risks and in investing during turbulent times, and also in targeting individuals at the bottom of the pyramid with innovation. Managers should formulate specific strategies to target individuals from emerging economies and individuals at the bottom of the pyramid. Such individuals have requirements and preferences which are different from that of individuals from developed economies. Market sizes of emerging economies are substantial and such markets require special attention of managers.

\subsection{Contributions of the Study}

The contribution of the paper lies in the fact that an in-depth discussion of the various strategies related to managing innovation in new product development was done. The discussions have both theoretical and practical implications. Based on the discussions presented, academicians may conduct a further review of the process of managing innovation in new product development and conduct an in-depth analysis of the approaches undertaken by companies to manage innovation in general and in specific situations of innovation in turbulent times and in targeting individuals at the bottom of the pyramid. They may suggest better strategies for managing innovation in new product development. Efforts were made to include the relevant and latest literature related to managing innovation in new product development. Managers may also benefit from the discussions presented. These are highlighted in the section covering managerial implications.

\section{CONCLUSION}

The paper discussed about the various aspects of managing innovation in new product development. Organizations should be willing and ready to adopt innovation. They should adopt a customer-centered, team-based, and systematic approach towards innovation. They should also realize that opportunities 
may exist in innovation for new product development in turbulent times and also in targeting individuals at the bottom of the pyramid. Innovative firms may gain the maximum benefits in such cases.

\subsection{Avenues for Future Research}

Innovation is an ever-evolving field with developments happening regularly. Researchers and practicing managers require keeping themselves updated about the latest trends and developments and suggest better approaches for managing innovation in new product development. Researchers may take cues from the discussions presented, analyze the various approaches taken by companies, and suggest new directions. At present, companies are focusing on developing new products for developing and emerging economies where the challenges are more than for developed economies. The requirements of emerging markets are different from that of developed markets. Research is required to analyze such requirements and product innovation should be done accordingly. 


\section{REFERENCES}

Aboulnasr, K., Narasimhan, O., Blair, E., \& Chandy, R. (2008). Competitive Response to Radical Product Innovation. Journal of Marketing, 72(3), 94-110. doi:10.1509/JMKG.72.3.094

Afriyie, S., Du, J., \& Musah, A. A. I. (2019). Innovation and marketing performance of SME in an emerging economy: The moderating effect of transformational leadership. Journal of Global Entrepreneurship Research, 9(1), 40. doi:10.1186/s40497-019-0165-3

Barone, M. J., \& Jewell, R. D. (2013). The Innovator's License: A Latitude to Deviate from Category Norms. Journal of Marketing, 77(1), 120-134. doi:10.1509/jm.10.0145

Berner, R. (2008, April 14). How P\&G Pampers New Thinking. BusinessWeek, 73-74.

Berner, R. (2009, April 13). How P\&G Plans to Clean Up. BusinessWeek, 44-45.

Bessant, J., Moslein, K., \& Stamm, B. V. (2009, March 22). In Search of Innovation. Wall Street Journal.

Breen, B. (2007, March). C. K. Prahalad: Pyramid Schemer. Fast Company.

Brinkman, L. (2013, July 11). 5 Things Google Glass Has Taught Me about Beta Testing. NewsOK.

Brown, T. (2009). Change by Design: How Design Thinking Transforms Organizations and Inspires Innovation. New York: HarperCollins.

Burrows, P. (2012, February 20-February 26). Google's Bid to Be Everything to Everyone. Bloomberg Businessweek, pp. 37-38.

Carus, F. (2012, August 29). Reverse Innovation Brings Social Solutions to Developed Countries. The Guardian.

Crawford, M., \& Di Benedetto, A. (2011). New Products Management (10th ed.). New York: McGraw-Hill.

Dahan, E., \& Hauser, J. R. (2002). Product Development: Managing a Dispersed Process. In B. Weitz \& R. Wensley (Eds.), Handbook of Marketing (pp. 179-222). London: Sage.

Epps, S. R. (2013, March 4). Project Glass: Google's Transparent Product Strategy Is Great Marketing, Too. Forrester.

Gamble, J. R., McAdam, R., \& Brennan, M. (2019). How User-centric Innovation is Affecting Stakeholder Marketing Strategies: Exploratory Findings from the Music Industry. European Management Review, 16(4), 1175-1193. doi:10.1111/emre. 12326

Govindarajan, V. (2012). A Reverse-Innovation Playbook. Harvard Business Review, 120-123.

Govindarajan, V., \& Trimble, C. (2012). Reverse Innovation: Create Far from Home, Win Everywhere. Boston, MA: Harvard Business School Publishing. doi:10.5437/08956308X5506003

Hauser, J. R., Tellis, G., \& Griffin, A. (2006). Research on Innovation: A Review and Agenda for Marketing Science. Marketing Science, 25(6), 687-717. doi:10.1287/mksc.1050.0144

Hayes, J. (2009, April 15). In a Tough Economy, Innovation Is King. Marketing News, pp. 14-17.

Immelt, J. R., Govindarajan, V., \& Trimble, C. (2009). How GE Is Disrupting Itself. Harvard Business Review, $87(10), 56-65$.

Jane, R. (2009, March 23). Inspiration from Emerging Economies. BusinessWeek, pp. 38-41.

Jhang, J. H., Grant, S. J., \& Campbell, M. C. (2012). Get It? Got It. Good! Enhancing New Product Acceptance by Facilitating Resolution of Extreme Incongruity. JMR, Journal of Marketing Research, 49(2), $247-259$. doi:10.1509/jmr.10.0428

Kahn, K. B. (2018). Understanding innovation. Business Horizons, 61(3), 453-460. doi:10.1016/j. bushor.2018.01.011

Lafley, A. G., \& Charan, R. (2009). The Game Changer: How You Can Drive Revenue and Profit Growth Through Innovation. New York: Crown Business. 
Landwehr, J. R., Wentzel, D., \& Herrmann, A. (2013). Product Design for the Long Run: Consumer Responses to Typical and Atypical Designs at Different Stages of Exposure. Journal of Marketing, 77(5), 92-107. doi:10.1509/ jm.11.0286

Liu, Y., Deng, P., Wei, J., Ying, Y., \& Tian, M. (2019). International R\&D alliances and innovation for emerging market multinationals: Roles of environmental turbulence and knowledge transfer. Journal of Business and Industrial Marketing, 34(6), 1374-1387. doi:10.1108/JBIM-01-2018-0052

Mansur, C. M., Suliyanto, S., \& Rahab, R. (2019). Value of Innovation and Marketing Performance. International Review of Management and Marketing, 9(3), 127-133. doi:10.32479/irmm.7761

Markides, C. C. (2012). How Disruptive Will Innovations from Emerging Markets Be? MIT Sloan Management Review, 54(1), 23-25.

Martin, R. L. (2011). The Innovation Catalysts. Harvard Business Review, 89(6), 82-87. PMID:21714388

Prahalad, C. K. (2010). The Fortune at the Bottom of the Pyramid. Upper Saddle River. NJ: Wharton School Publishing.

Psomas, E., Kafetzopoulos, D., \& Gotzamani, K. (2018). Determinants of company innovation and market performance. The TQM Journal, 30(1), 54-73. doi:10.1108/TQM-07-2017-0074

Rajapathirana, R. J., \& Hui, Y. (2018). Relationship between innovation capability, innovation type, and firm performance. Journal of Innovation \& Knowledge, 3(1), 44-55. doi:10.1016/j.jik.2017.06.002

Rigby, D. K., Gruver, K., \& Allen, J. (2009). Innovation in Turbulent Times. Harvard Business Review, 87(6), 79-86.

Rogers, E. M. (2003). Diffusion of Innovation (5th ed.). New York: Simon \& Schuster.

Rubera, G., \& Kirca, A. H. (2012). Firm Innovativeness and Its Performance Outcomes: A Meta Analytic Review and Theoretical Integration. Journal of Marketing, 76(3), 130-147. doi:10.1509/jm.10.0494

Salter, C. (2008, March). Google: The Faces and Voices of the World's Most Innovative Company. Fast Company, pp. 74-88.

Stone, B. (2013, May 22). Inside the Moonshot Factory. Bloomberg Businessweek.

Tellis, G. J., Prabhu, J. C., \& Chandy, R. K. (2009). Radical Innovation across Nations: The Preeminence of Corporate Culture. Journal of Marketing, 73(1), 3-23. doi:10.1509/jmkg.73.1.003

Troy, L. C., Hirunyawipada, T., \& Paswan, A. K. (2008). Cross-Functional Integration and New Product Success: An Empirical Investigation of the Findings. Journal of Marketing, 72(6), 132-146. doi:10.1509/jmkg.72.6.132

Winslow, G. (2012, January 12). Two-Thirds of U.S. Households Have HDTV. TVNewsCheck.

Pratap Chandra Mandal is an Assistant Professor (Marketing) at the Indian Institute of Management, Shillong, India. He has completed graduate degree from the reputed Indian Institute of Technology, Kharagpur (IIT Kharagpur), India (Bachelor of Technology in Mechanical Engineering), post-graduate degree from Vinod Gupta School of Management, IIT Kharagpur (Masters in Business Administration), PhD (Marketing) from Vinod Gupta School of Management, IIT Kharagpur. His research concerns customer relationship management, customer satisfaction, services marketing, marketing intelligence, and qualitative methods in management. He is the editor-in-chief of two international journals and is on the editorial board of journals like the "Journal of Global Marketing." Pratap has won several prestigious scholarships and awards throughout his academic career. 